\title{
PanAfrican Medical

\section{Baseline CD4+ $T$ lymphocyte cell counts, hepatitis B and C viruses seropositivity in adults with Human Immunodeficiency Virus infection at a tertiary hospital in Nigeria}

\author{
Ebenezer Adekunle Ajayi ${ }^{1, \&}$, Akande Oladimeji Ajayi ${ }^{1}$, Patrick Temi Adegun ${ }^{2}$, Iyiade Adeseye Ajayi ${ }^{3}$, Abiodun Akinyeye Ojo ${ }^{4}$, \\ Hussean Taiwo Raimi ${ }^{1}$ \\ ${ }^{1}$ Department of Medicine, University Teaching Hospital, Ado Ekiti, Nigeria, ${ }^{2}$ Department of Surgery, University Teaching Hospital, Ado Ekiti, Nigeria, \\ ${ }^{3}$ Department of Ophthalmology, University Teaching Hospital, Ado Ekiti, Nigeria, ${ }^{4}$ Department of Hematology, University Teaching Hospital, Ado \\ Ekiti, Nigeria
}

${ }^{\&}$ Corresponding author: Ebenezer Adekunle Ajayi, Department of Medicine, University Teaching Hospital, Ado Ekiti, Nigeria

Key words: HIV AIDS infection, CD4+ T-lymphocyte cell counts, Hepatitis B virus infection

Received: 15/12/2010 - Accepted: 18/04/2011 - Published: 21/05/2011

\begin{abstract}
Background: Ekiti State of Nigeria is known to have the lowest prevalence of HIV in Nigeria. University Teaching Hospital (UTH), Ado Ekiti was recently upgraded to serve as one of the three centres for HIV/AIDS referral, diagnosis and treatment in Ekiti State. We evaluated the baseline immunologic and biochemical parameters of patients presenting at the ART clinic of University Teaching Hospital, Ado Ekiti, Ekiti State. Methods: All HIV seropositive patients not yet on antiretroviral therapy, who presented at the ART Clinic within the study period had at the first visit to the clinic, their blood sample taken for CD4 cell counts estimation, HBsAg and anti- HCV screening, ALT, AST as well as hemoglobin estimation as part of the routine workup to assess their disease health status and need for antiretroviral therapy. Statistical significance was taken as $\mathrm{p}<0.05$. Results: A total of 273 patients comprising $79(28.9 \%)$ males and $194(71.1 \%)$ females were included in the study (F:M = 2.46: 1$)$. The mean age of the study population was $36.21 \pm 10.20$ years with mean age of males (39.52 \pm 9.95 years) significantly higher than females ( $34.88 \pm$ $10.02 ; p=0.001$ ). The overall prevalence of HBsAg in the study population was $6.6 \%$ with a sex specific prevalence of $8.1 \%$ and $6 \%$ for males and females, respectively. No statistically significance difference in the mean serum alanine transaminase, serum aspartate transaminase, hemoglobin and CD4+ T- Lymphocytes cell count of those who had HBsAg negative status compared to those who had HBsAg positive status. Two (0.7\%) of

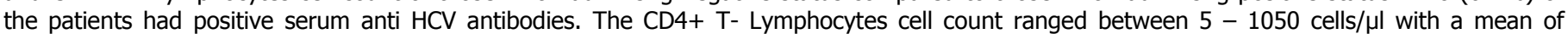
$286.19 \pm 233.31$ cells/ $\mu$ l. The majority of patients $(71.8 \%)$ had a CD4+ T- Lymphocytes cell count < 350 cells/ $\mu$ l. Conclusion: At the time of presentation, majority of our patients had a CD4+ T- Lymphocytes cell count less than $350 \mathrm{cells} / \mu \mathrm{l}$ consistent with significant immune-suppression. More sustained and vigorous awareness campaigns still need to be done in Ekiti State to diagnose this disease early. There is also a need to accelerate the integration of hepatitis B virus screening and treatment programme into HIV/AIDS programme because of the morbidity and mortality implication of HBV and HIV co-infection.
\end{abstract}

Pan African Medical Journal. 2011; 9:6

This article is available online at: http://www.panafrican-med-journal.com/content/article/9/6/full/

(c) Ebenezer Adekunle Ajayi et al. The Pan African Medical Journal - ISSN 1937-8688. This is an Open Access article distributed under the terms of the Creative Commons Attribution License (http://creativecommons.org/licenses/by/2.0), which permits unrestricted use, distribution, and reproduction in any medium, provided the original work is properly cited. 


\section{Background}

HIV infection is a global pandemic. By the end of 2007 it was estimated that about 33.2 million people were living with HIV in the world with more than $60 \%$ of the infected population in sub-Saharan Africa [1]. In Nigeria, the prevalence of HIV among adults during the year 2007 was $3.1 \%$ [2]. In that year 2007, 170,000 deaths of the estimated 2.6 million people living with HIV/AIDS were reported. In response to the global efforts at improving care and treatment, the Nigeria Government in collaboration with various partners run HIV care and treatment that included the provision of free antiretroviral drugs and drugs for opportunistic infections.

Despite the enormous attention being paid to early diagnosis and treatment of HIV/AIDS worldwide, reports still showed that most patients still present late for care [3-5]. The impact of this on morbidity and mortality vis-à-vis the reduced immunologic status at presentation had also been documented $[6,7]$. In addition, the common routes of infection shared by HIV, HBV and HCV [8] have generated interests in co-infection between $\mathrm{HIV}, \mathrm{HBV}$ and/or HCV. As a matter of facts, about $5 \%$ to $10 \%$ of HIV patients harbor persistent serum HBsAg and therefore suffer from chronic hepatitis B [9]. Progression to end-stage liver disease occurs more quickly in HIV/HBV-coinfected patients; this is characteristic in the absence of significant elevations in liver enzymes, as inflammatory phenomena in the liver are ameliorated in HIV infection although paradoxically fibrogenesis is enhanced. Liver disease is currently one of the leading causes of morbidity and mortality in HIV - infected individuals with chronic hepatitis B and hepatitis $\mathrm{C}$ being the major causes of hepatic disease in this population [10]. Though, screening for hepatitis B and C viruses in HIV-infected individuals is becoming widespread, integration of the treatment of these viral hepatitides has not been achieved in most countries, including Nigeria.

The objectives of this study were to: (1) determine the baseline CD4+ T Lymphocytes cell count and haemoglobin level in antiretroviral naïve HIV patients; (2) determine the prevalence rates at baseline of HBsAg and anti- hepatitis C antibody (HCV-ab) sero-positive status in this population of HIV patients who presented at the ART Clinic of a recently upgraded centre for HIV/AIDS referral, diagnosis and treatment in Ekiti State, southwestern Nigeria (where HIV prevalence at $1 \%$ is the lowest in Nigeria).

\section{Methods}

This study was carried out at the medical department of the University Teaching Hospital (UTH), Ado-Ekiti, Nigeria, in the period January 2009 March 2010 (15 months period). This centre is one of the three recently upgraded centres in Ekiti State, Southwestern Nigeria to provide care and treatment including provision of free antiretroviral drugs for HIV/AIDS referral, diagnosis and treatment. Usually, in our Centre, HIV Testing and Counseling (HCT) is routine in all the clinical service areas, in addition to the quarterly community HCT outreaches where subjects' capillary blood samples are screened for HIV by the use of two nationally approved rapid HIV kits run in parallel (Determine ${ }^{\mathrm{TM}}$ HIV-1/2, Abbot Laboratories, USA and STAT-PAKR HIV- 1/2, Chembio Diagnostic Systems, Inc, USA). Those who are HIV positive are thereafter referred to ART clinic for enrollment into HIV care. A total of 7,122 subjects were thus screened during the study period.

All HIV seropositive patients who were antiretroviral therapy naïve and who presented at the ART Clinic within the study period had at the first visit to the clinic, their blood sample taken for CD4 cell counts estimation, HBsAg and anti- HCV screening, ALT, AST as well as hemoglobin estimation as part of the routine workup to assess their disease health status and need for antiretroviral therapy. Freshly taken blood sample drawn into a 2$\mathrm{mL}$ Ethylene Diamine Tetra-acetic Acid (EDTA) anticoagulant bottle and processed within 2 hours of venesection, was used to estimate CD4+ T Lymphocytes cell counts; screened for HBsAg and HCV-ab; as well as estimation of haemoglobin concentration. Samples for CD4+ T Lymphocytes cell counts were prepared and run on the Cyflow SL 3 (Partec Inc., Germany) according to the manufacturer's instructions. Qualitative detection of $\mathrm{HBsAg}$ and HCV-ab in plasma was done using rapid diaspot one step strip (Sam Tech Diagnostics). Haemoglobin concentration estimation was done with the use of Haemocue haemoglobin concentration machine (HaemoCue AB Angelholm, Sweden). Alanine transaminase (ALT) and aspartate transaminase (AST) were determined by colorimetric method using the Randox kit (Randox Laboratories Ltd, UK) with absorbance read on a spectrophotometer at a wavelength range of 530-560 nanometer.

The laboratory dedicated to HIV care in our Centre is routinely subjected to internal quality control assessment using the Manufacturers' prepared kit or test solution as well as quarterly external quality control using a reference laboratory supervised by the Institute of Human Virology of Nigeria.

The protocol for this study was approved by the Research and Ethic Committee of the University Teaching Hospital, Ado Ekiti.

\section{Statistical analysis}

Data were expressed as mean \pm standard deviation (SD), and frequency and were expressed as numbers and percentages. Computation of $P$ values was done by t-test and chi-squared analysis. $\mathrm{P}<0.05$ was considered statistically significant. All statistical analyses were performed with the commercially available computer program SPSS 11.0 (SPSS Inc., Chicago, IL).

\section{Results}

The mean age of the 273 patients was $36.21 \pm 10.20$ years (range $16-79$ years). There were $79(28.9 \%)$ males and 194 (71.1\%) females giving a male to female ratio of $1: 2.46$. The males, with a mean age of $39.52 \pm 9.95 y e a r s$ were significantly older than females whose mean age was $34.88 \pm 10.02 ; p=0.001$. Majority of the patients (71.1\%) were within the age group $21-40$ years. The majority (79.2\%) was married at the time of presentation and only $8 \%$ of them did not have any form of formal education. 
Eighteen patients were HBsAg sero-positive giving a sero-positive prevalence of $6.6 \%$ among the study population. Frequency of positive serum $\mathrm{HBsAg}$ was $8.1 \%$ and $6 \%$ among males and females respectively. When the HBsAg sero-negative patients were compared with those who were

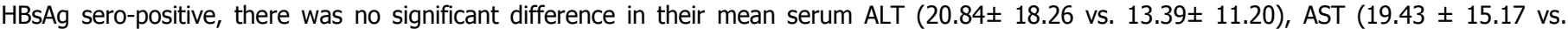
$12.14 \pm 5.49)$, hemoglobin $(10.23 \pm 2.33$ vs. $11.46 \pm 1.28)$ and CD4+ T Lymphocytes cell count (258.13 \pm 211.16 vs. $234.07 \pm 178.34)$. Serum antiHCV antibody was positive in 2(0.7\%) of the 273 patients studied. Distribution of the number of seropositive patients for HBsAg and anti-HCV antibody according to age groups is shown in table 1 while table 2 provides the baseline ALT, AST and Hemoglobin in different strata of CD4+ T lymphocyte cell count.

The mean CD4+ T Lymphocytes cell count of the study population was $286.19 \pm 233.31$ (range 5- 1,051). The mean CD4+ T Lymphocytes cell count of the males was $293.95 \pm 244.53$, while that for females was $283.47 \pm 229.96 ; p=0.77$. The CD4+ T Lymphocytes cell count of majority of the patients $(71.8 \%)$ was $<350$ cells $/ \mu l$.

The mean haemoglobin was $10.34 \pm 2.25 \mathrm{~g} / \mathrm{dl}$. Males $(11.06 \pm 2.18 \mathrm{~g} / \mathrm{dl})$ had significantly higher mean haemoglobin than females $(10.05 \pm$ $2.22 \mathrm{~g} / \mathrm{dl} ; \mathrm{p}=0.004)$. Sixty five percent had hemoglobin $\geq 10 \mathrm{~g} / \mathrm{dl}$. Among the males, $22.8 \%$ had hemoglobin $<10 \mathrm{~g} / \mathrm{dl}$ while $39.9 \%$ of the females had haemoglobin $<10 \mathrm{~g} / \mathrm{dl}(\mathrm{p}=0.016)$. Mean hemoglobin reduced progressively as the serum CD4+ T Lymphocytes cell count declined.

\section{Discussion}

In this study, majority of the patients first presented to the centre at a time when the CD4+ T Lymphocytes cell count was already in the range requiring commencement of ART. This shows that most of our patients still present late to the hospital. Quite a large percentage (45.5\%) of our patients had a CD4+ T Lymphocytes cell count $<200$ cells/ $\mu \mathrm{L}$ at presentation and about $72 \%$ had CD4+ T Lymphocytes cell count $<350$ cells/ $\mu \mathrm{L}$. Earlier reports from Northern Nigeria showed that 50-54\% of HIV patients had CD4+ T Lymphocytes cell count $<200$ cells/ $\mu \mathrm{L}$ at presentation $[11,12]$. Other African ART programs have also reported low CD4+ T Lymphocytes cell count at enrollment for adult ART [13-15]. In a study in India [16] where $43 \mathrm{HIV}$ patients who were antiretroviral naïve were studied to determine correlation between CD4+ T Lymphocytes cell count and plasma viral load, all the patients had their CD4+ T Lymphocytes cell count $<200$ cells/ $\mu \mathrm{L}$ at presentation . The major reason for this high proportion of HIV patients presenting with low CD4+ T Lymphocytes cell count is late presentation.

Late presentation of HIV patients for care is definitely not a problem that is peculiar to our environment. Between $10 \%$ to $30 \%$ of HIV-infected individuals in the Western world reported to present late for care [3,4] and higher percentage in developing countries, particularly in sub-Saharan Africa, South-East Asia and South America, because of the limited access to healthcare and HIV treatment [5]. Stigma and delay in seeking health care, reluctance to utilizing voluntary testing and counseling services, and health system delays in referral and ART initiation are other possible explanations. Thus, priority must be given to identifying HIV-infected individuals and starting treatment earlier in the course of their illness, before they develop severe opportunistic infections. More sustained and vigorous awareness campaigns still need to be done to diagnose this disease early.

The mean hemoglobin in the population was low with males having significantly higher mean hemoglobin compared to females. Mean hemoglobin reduced progressively as the serum CD4+ T Lymphocytes cell count declined. It is known that the incidence of anemia increases with progression of HIV infection [17] which is the case in the present study. Furthermore, in this population of HIV patients with low CD4+ T Lymphocytes cell count, anemia can be a feature of certain opportunistic diseases, like disseminated mycobacterial infection and parvovirus B19. Other etiologic factors that may be involved in the development of HIV-associated anemia include micronutrient deficiencies, immunological myelosuppression, impaired erythropoietin production and blood loss from intestinal opportunistic disease [18].

There is need for enhanced interest in HIV/HBV co-infection. Around $5 \%$ to $10 \%$ of HIV patients harbor persistent serum HBsAg and therefore suffer from chronic hepatitis B [9]. Progression to end-stage liver disease occurs more quickly in HIV/HBV-coinfected patients; this is characteristic in the absence of significant elevations in liver enzymes, as inflammatory phenomena in the liver are ameliorated in HIV infection although paradoxically fibrogenesis is enhanced. The overall prevalence of $\mathrm{HBsAg}$ in our study population was $6.6 \%$ with a sex specific prevalence of $8.1 \%$ and $6 \%$ for males and females, respectively. However, the rate for HCV-Ab (0.7\%) was lower than the rate for HBsAg. Liver enzymes in this study were found not to be significantly elevated. The rates of HBsAg and HCV-Ab co-infections with HIV in our study are comparable with findings in other studies. For instance, results of an earlier study in Nigeria conducted on 1779 HIV-positive patients revealed that the rates for HBsAg, HCV, and $\mathrm{HBV} / \mathrm{HCV}$ coinfections were $11.9,4.8$, and $1 \%$, respectively [19]. Moreover, in India, a study showed that the prevalence rate of HBsAg in HIV-positive patients was 3.4\% while the rate for HCV-Ab was reported to be $0 \%$ [20]. The prevalence rates of co-infection with HBV and HCV in HIV patients have been variable worldwide depending on the geographic regions, risk groups and the type of exposure involved which may be different not only from country to country, but also in different regions of the same country $[9,21]$. It is known that sexual transmission of HCV is lower in comparison to HBV and it is transmitted mostly via injection (especially in drug addiction). This may explain why the rate of HIV/HCV in our study was low since sexual transmission is the commonest root of infection in our environment [8]. Undoubtedly, it is important to fully integrate HBV and HCV diagnosis in HIV-positive patients in order to take care of them and allot resources in health plans.

Interestingly, hepatitis B virus infection is preventable. This can be achieved by similar measures taken to prevent the transmission of HIV infection such as safe sex practice, safe handling of sharps, and avoidance of sharing of intravenous drug paraphernalia, among others. In addition, safe and effective vaccines with probably lifelong immunity against all hepatitis B virus serotypes and genotypes are currently available [22].

The majority of our study population was within the age group 21-40 years which is in keeping with our country National survey [23] and global findings on the age group of patients most affected with HIV [1]. We also found in the present study that more HIV- infected females (71.1\%) presented for care at a significantly younger age (34.88 \pm 10.02 years) compared with males (28.9\%) with the mean age at presentation of 39.52 \pm 9.95 years. This is similar to the findings by Otegbayo [19] et al and Ajayi et al [15]. However, this is in contrast with the National sero- 
prevalence survey reported in 2003 where there was higher ratio of males to females usually seen in early phase of epidemic but tend to reverse as the epidemic matures. Whether this reversal in ratio of males to females seen in maturing epidemic was the case in this study or evidence that HIV sero-positive women seek health care more than HIV sero-negative men are issues that future survey should elucidate. It must be noted, however, that women of reproductive ages may have better access to HIV testing and counseling (HCT) than men through antenatal care services where $\mathrm{HCT}$ is now made compulsory.

\section{Conclusion}

At the time of presentation, majority of our patients had a CD4+ T Lymphocytes cell count less than 350 cells/ $\mu$ l consistent with significant immune-suppression. Despite the low prevalence of HIV in Ekiti State, more sustained and vigorous awareness campaigns still need to be done in order to diagnose this disease early and encourage early presentation at the health care facility for those who are sero-positive. There is also a need to accelerate the integration of hepatitis B virus screening and treatment programme into HIV/AIDS programme because of the morbidity and mortality implication of HBV and HIV co-infection.

\section{Competing interests}

The authors declare no competing interests.

\section{Authors' contributions}

ICMJE authorship criteria read and met. EA AJAYI conceived, partly designed, analysed and interpreted the data. He drafted the background and results section of this manuscript. He also contributed substantially to the discussion segment. AO AJAYI partly designed this study. He collected the data and interpreted the data. He also contributed substantially to the discussion segment. PT ADEGUN collected data, interpreted and also contributed to the discussion segment. He revised the manuscript. AI AJAYI partly designed, analysed and interpreted the data. She contributed substantially to the discussion segment and proof read the final version of this manuscript. AA OJO partly designed this study. He collected the data and interpreted the data. He also contributed substantially to the final version of the manuscript. HT RAIMI. He collected the data and interpreted the data. He also contributed substantially to the final version of the manuscript. All authors have read and approved the final version of the manuscript.

\section{Acknowledgements}

This publication was supported by Cooperative Agreement Number PS000651-03 from Centers for Disease Control and Prevention (CDC). Its contents are solely the responsibility of the authors and do not necessarily represent the official views of CDC.

\section{Tables}

Table 1: Baseline distribution of CD4+ T lymphocyte cell count, Hemoglobin, and HBsAg and HCV positive status by age groups in a group of adults with Human Immunodeficiency Virus infection at a tertiary hospital in Nigeria

Table 2: Baseline ALT, AST and Hemoglobin in different strata of CD4- T lymphocyte cell count in a group of adults with Human Immunodeficiency Virus infection at a tertiary hospital in Nigeria

\section{References}

1. United Nations Programme on HIV/AIDS (UNAIDS). World Health Organization (WHO), AIDS epidemic update: December 2007. http://www.unaids.org/en/media/unaids/contentassets/restore/jc1510_2008_global_report_pp211_234_en.pdf. Accessed 16 December 2010

2. UNAIDS Report on the global AIDS Epidemic 2010. http://www.unaids.org/globalreport/Global_report.htm. Accessed 16 December 2010

3. Sabin $\mathrm{CA}$, Smith $\mathrm{CJ}$, Gumley $\mathrm{H}$, et al. Late presenters in the era of highly active antiretroviral therapy: uptake of and responses to antiretroviral therapy. AIDS. 2004 Nov 5;18(16):2145-51.. This article on PubMed

4. Braitstein P, Brinkhof MW, Dabis F, et al. Mortality of HIV-1-infected patients in the first year of antiretroviral therapy: comparison between low-income and high-income countries. Lancet. 2006 Mar 11;367(9513):817-24.. This article on PubMed

5. Sepkowitz KA. One disease, two epidemics-AIDS at 25. N Engl J Med. 2006 Jun 8;354(23):2411-4. This article on PubMed

6. Hogg RS, Yip B, Chank KJ, Wood E, Craib KJ, O'Shaughnessy MV, et al. Rates of disease progression by baseline CD4 cell count and viral load initiating triple drug therapy. JAMA. 2001;286:2568-2577. This article on PubMed 
7. Garcia F, De Lazzari E, Plana M, Castro P, Mestre G, Nomdedeu M, et al. Long term CD4+ T-cell response to HAART according to baseline CD4 + t-cell count. J Acquir Immune Defic Syndr. 2004 Jun 1;36(2):702-13. This article on PubMed

8. De Kock, K M, E Ekpini, E Gnaore, A Kadio and H D Gayle. The public health implications of AIDS research in Africa. JAMA. 1994; 272: 481-486. This article on PubMed

9. Alter M. Epidemiology of viral hepatitis and HIV co-infection. J Hepatol. 2006;44(1 Suppl):S6-9. This article on PubMed

10. Weber R, Sabin C, Friis-Moller N, Reiss P, El-Sadr W, Kirk O, et al. Liver-related deaths in persons infected with the HIV: the D:A:D study. Arch Intern Med. 2006; 166:1632-1641. This article on PubMed

11. Nwokedi EE, Ochicha O, Mohammed AZ, Saddiq NM. Baseline CD4 lymphocyte count among HIV patients in Kano, Northern Nigeria. Afr J Health Sci,. 2007; 14:212-215

12. Njoku MO, Sirisena ND, Idoko JA, Jelpe D. CD4+ T-lymphocyte counts in patients with human immunodeficiency virus type 1 (HIV-1) and healthy population in Jos, Nigeria. Niger Postgrad Med J. 2003 Sep;10(3):135-9. This article on PubMed

13. Gautam H, Bhalla P, Saini S, Dewan R. Correlation between baseline CD4 + T-Lymphocyte count and plasma viral load in AIDS patients and their early clinical and immunological response to HAART: A preliminary study. Indian J Med Microbiol. 2008; 26(3): 256-258. This article on PubMed

14. Zachariah R, Fitzgerald M, Massaquoi M, Pasulani O, Arnould L, Makombe $S$, Harries AD. Risk factors for high early mortality in patients on antiretroviral treatment in a rural district of Malawi. AIDS. 2006; 20:2355-2360. This article on PubMed

15. Ajayi AO, Ajayi EA, Fasakin KA. CD4+ T-Lymphocytes cell counts in adults with human immunodeficiency virus infection at the medical department of a tertiary health institution in Nigeria. Ann Afr Med. 2009;8:257-260. This article on PubMed

16. Lawn SD, Myer L, Harling G, Orrell C, Bekker LG, Wood R. Determinants of mortality and nondeath losses from an antiretroviral treatment service in South Africa: implications for program evaluation. Clin Infect Dis. 2006; 43:770-776. This article on PubMed

17. Sullivan PS, Hanson DL, Chu SY, Jones JL, Ward JW. Epidemiology of anemia in human immunodeficiency virus (HIV)-infected persons: results from the multistate adult and adolescent spectrum of HIV disease surveillance project. Blood. 1998; 91:301-308. This article on PubMed

18. Semba RD, Gray GE. Pathogenesis of anemia during human immunodeficiency virus infection. J Investig Med. 2001; 49:225-239. This article on PubMed

19. Otegbayo JA, Taiwo BO, Akingbola TS, Odaibo GN, Adedapo KS, Penugonda S, Adewole IF, Olaleye DO, Murphy R, Kanki P. Prevalence of hepatitis B and C seropositivity in a Nigerian cohort of HIV-infected patients. Annals of Hepatology. 2008; 7:152-156. This article on PubMed

20. Mahajan A, Tandon VR, Verma S, Singh JB, Sharma M. Prevalence of Tuberculosis, Hepatitis B, Hepatitis C and Syphilis Co-infections among HIV/AIDS Patients. Indian Journal of Medical Microbiology. 2008; 26:196-207. This article on PubMed

21. Rockstroh JK. Management of hepatitis B and C in HIV coinfected patients.J Acquir Immune Defic Syndr. 2003 Sep;34 Suppl 1:S59-65. This article on PubMed

22. Lavanchy D. Hepatitis B virus epidemiology, disease burden, treatment, and current and emerging prevention and control measures. J Viral Hepat 2004; 11:97-107. This article on PubMed

23. Federal Ministry of Health. 2003 National HIV Seroprevalence Sentinel Survey. Abuja: Federal Ministry of Health, 2003. Unpublished 
Table 1: Baseline distribution of CD4- T lymphocyte cell count, Hemoglobin, and HBsAg and HCV positive status by age groups in a group of adults with Human Immunodeficiency Virus infection at a tertiary hospital in Nigeria

\begin{tabular}{|c|c|c|c|c|c|c|c|}
\hline \multirow[t]{2}{*}{ Variable } & $\leq \mathbf{2 0}$ & $21-30$ & $31-40$ & 41-50 & $51-60$ & $>60$ & \multirow{2}{*}{$\begin{array}{c}\text { P } \\
\text { value }\end{array}$} \\
\hline & $(n=7)$ & $(n=91)$ & $(n=103)$ & $(n=34)$ & $(n=8)$ & $(n=3)$ & \\
\hline CD4 cell count (cells/ $\mu \mathrm{l})$ & $492.33 \pm 355.15$ & $296.49 \pm 225.41$ & $285.88 \pm 243.18$ & $248.62 \pm 219.20$ & $263.22 \pm 182.99$ & $254.00 \pm 81.62$ & 0.294 \\
\hline $\operatorname{Hemoglobin}(\mathrm{mg} / \mathrm{dl})$ & $11.00 \pm 3.16$ & $10.23 \pm 2.54$ & $10.40 \pm 2.27$ & $10.48 \pm 1.73$ & $9.47 \pm 2.36$ & $10.92 \pm 1.29$ & 0.783 \\
\hline HBsAg positive & 2 & 8 & 6 & 0 & 2 & 0 & 0.682 \\
\hline \multicolumn{8}{|l|}{ status(n) } \\
\hline HCV positive status $(\mathrm{n})$ & 0 & 1 & 0 & 1 & 0 & 0 & 0.234 \\
\hline
\end{tabular}

Table 2: Baseline ALT, AST and Hemoglobin in different strata of CD4- T lymphocyte cell count in a group of adults with Human Immunodeficiency Virus infection at a tertiary hospital in Nigeria

\begin{tabular}{|c|c|c|c|c|c|}
\hline \multirow[b]{2}{*}{ Variable } & \multicolumn{5}{|c|}{ Strata of CD4- T lymphocyte cell count } \\
\hline & $\geq \mathbf{5 0 0}$ & $350-499$ & $200-349$ & $<200$ & $P$ value \\
\hline $\begin{array}{l}\text { Serum aspartate } \\
\text { transaminase }(\mathrm{mmol} / \mathrm{l})\end{array}$ & $15.00 \pm 5.70$ & $12.00 \pm 6.71$ & $20.72 \pm 19.72$ & $19.35 \pm 15.00$ & 0.35 \\
\hline $\begin{array}{l}\text { Serum alanine } \\
\text { transaminase }(\mathrm{mmol} / \mathrm{l})\end{array}$ & $20.40 \pm 12.86$ & $15.86 \pm 7.61$ & $20.83 \pm 18.47$ & $17.43 \pm 14.08$ & 0.59 \\
\hline Haemoglobin(mg/dl) & $10.97 \pm 2.37$ & $10.87 \pm 1.89$ & $10.83 \pm 1.93$ & $9.81 \pm 2.36$ & 0.01 \\
\hline
\end{tabular}

